graphs or drawings of a cloud chamber, Geiger counter, electrostatic generator, linear accelerator, cyclotron, synchrotron, betatron and bevatron, all in the space of eighteen pages. There are a number of misprints and errors, which were particularly noticeable near the beginning of the book, some sixteen having been counted in the first one hundred pages. In a description (p. 65) of an experiment to demonstrate the corpuscular nature of light, the sense of the experiment is lost, and criticism of the Fermi theory of beta-decay (p. 281) is misdirected. On p. 284 it is stated that "The first induced transformation of this kind was discovered in 1919 , though by no means intentionally, by Rutherford when he bombarded pure nitrogen with alpha particles".

Scientific lapses of the kind mentioned above are, however, very infrequent, and a high standard of scientific exposition and clarity is maintained. This would seem a useful book to have available in science libraries.

A. G. WARD

\section{TRACER TECHNIQUE}

\section{Radioactive Tracer Techniques}

By Prof. Geo. K. Schweitzer and Ira B. Whitney. Pp. vi+241. (New York: D. Van Nostrand Co., Inc.; London : Macmillan and Co., Ltd., 1949.) 16s. net.

\section{Introduction to Radiochemistry}

By Gerhart Friedlander and Prof. Josoph W. Kennedy. Pp. xiii +412 . (New York : John Wiley and Sons, Inc.; London: Chapman and Hall, Ltd., 1949.) 40s, net.

Isotopic Tracers and Nuclear Radiations

With Applications to Biology and Medicine. By William E. Siri. Pp. xiii +653 . (New York and London: MeGraw-Hill Book Co., Inc., 1949.) 106s. $6 d$.

7 'HE use of isotopes as 'indicators', or 'tracers', in all sorts of scientific and technical problems is by now widespread. Its adoption by still more laboratories is quite often hampered by the lack of trained workers; but instruction courses in various centres try to provide the necessary number of experts, and a further essential help is given by several books recently published. Since the kind and degree of training needed varies from place to place, it is gratifying to see that authors try to cater for this diversity of needs. The three books under review are examples of this variety.

The manual on "Radioactive Tracer Techniques", by Prof. G. K. Schweitzer and I. B. Whitney, is meant for beginners, and considers almost exclusively the practical side. True to the sound principle of 'safety first', it is very emphatic in impressing on its readers in Chapter 1 the necessity to take precautions for the protection of health and the avoidance of contamination. Detailed descriptions follow for the best lay-out of a radiochemical laboratory of moderate size, with recommendations of suitable material for floors and walls. Further chapters deal with chemical, physical and biological experiments and the tracer solutions required for them; the added list of commercial organizations supplying equiprnent and radioactive material quite naturally takes into consideration only the American market. A small table of nuclides "of tracer interest" is also provided; the modest size of the book does not allow for inclusion of more than the most common tracers, but the beginner will be thankful for these limitations.

G. Friedlander and Prof. J. W. Kennedy's "Introduction to Radiochemistry" goes considerably deeper into the matter. Its aim is to give the reader first of all the theoretical knowledge necessary for those who want to make the best use of the possibilities offered by the tracer technique. In spite of its title, it devotes several chapters to subjects usually considered as belonging not to radiochemistry but to the domain of physics, like nuclear structure and nuclear reactions, sources of bombarding particles, and measuring instruments. The matter is presented in a very clear, concise and competent way, roflecting the great experience gained by the authors in the instruction courses they have conducted for many years. As a special merit of the book may be mentioned the excellent chapters on "Statistical Considerations in Radioactivity Measurements", "Identification, Concentration, and Isolation of Radioactive Species", and "Chemistry of Low Concentrations".

An appendix contains, on more than ninety pages, a table of the radioactive and stable isotopes of all the elements up to curium, and a table of crosssections for neutron activation. At the end of each chapter there is a collection of excreises for the student (mainly calculations) and a list of references. The book will be found most useful by all who have to conduct, or attend, courses in radiochemistry, and also by many research workers.

W. E. Siri's stately volume on "Isotopic Tracers and Nuclear Radiations" is too voluminous to form tho basis of an instruction courso for students, but will prove of the greatest value to research workers on biological and other subjects. Although the author modestly states that it was his intention to compile "some of the material that appears to bo most essential to applications of isotopic tracers and nuclear reactions", with the help of a number of contributing authors he has produced a handbook so rich in information that frequently it will save the trouble of looking up the widely scattered original literature. (Only one small misprint has been noted : on p. 537 instead of $\mathrm{RaB}$ read $\mathrm{RaC}$, and instead of RaC read $\mathrm{RaC}^{\prime}$.) The book consists of three parts, "Isotopes and Nuclear Radiations", "Methods and Instruments" and "Biological and Medical Applications of Isotopes", this last part being contributed entirely by Dr. E. C. Dougherty. It is characteristic of this book that - in contrast with the two treatises mentioned before-inactive isotopes and their uses receive as much attention as the radioactive ones; in the second part we find aceordingly a chapter of some thirty pages describing the various types of mass spectrographs. Compared with the attention given to these and other physical apparatus and methods (counters, cyclotrons, betatrons, synchro. trons, ete.), the space devoted to chemical techniques is not great; as a matter of fact, Friedlander and Kennedy's book is in this respect much more informative. One of the most valuable features of Siri's handbook is the wealth of tables, diagrams and references to the literature; in addition to the lists given at the end of each chapter, there is an extensive bibliography in which the papers are arranged according to the radioactive or inactive nuclides employed as tracers. These few remarks must suffice to indicate the contents of an outstanding book, too comprehensive to be described in detail.

F. A. Paneth 